\title{
Vera Nünning The Ethics of (Fictional) Form: Persuasiveness and Perspective Taking from the Point of View of Cognitive Literary Studies
}

DOI 10.1515/arcadia-2015-0004

\begin{abstract}
The persuasive power of narratives, which has been demonstrated in a host of psychological experiments, offers a rewarding field of research for literary studies in general and ethical criticism in particular. If fictional as well as factual narratives can change the beliefs of readers, then they are ethically meaningful to disseminate values, emotional dispositions, and cognitive practices. Building on recent research in psychology and literary studies, this article explores in three steps the ethical value of fictional narratives. First, the persuasive power of narratives is discussed from a cognitive perspective, which includes consideration of the ethical consequences of taking the perspectives of others. Second, these insights are connected to a delineation of narrative conventions, which can foster the kind of deeper understanding associated with altruistic behavior. In the third part, pertinent narrative strategies are discussed from an ethical perspective. A brief conclusion summarizes the most important results and sketches some fields that merit exploration in future studies of ethical criticism.
\end{abstract}

Keywords: cognitive narratology, narrative conventions, persuasion, ethics, perspective taking

Narratives are persuasive: they can induce listeners to change their values and opinions. But even though the persuasive power of narrative is taken for granted and exploited in fields such as marketing and politics, literary scholars have as yet been reluctant to acknowledge this potential of narrative. Psychologists have tried to understand which kinds of narrative are more persuasive than others, but

Vera Nünning: Heidelberg University, Seminarstr. 2, 69117 Heidelberg, Germany, E-Mail: vera.nuenning@urz.uni-heidelberg.de 
literary scholars have not invested a lot of energy on that score. ${ }^{1}$ This is arguably a less than satisfying state of affairs, not least as the power of narratives to influence readers offers a rewarding area of research for literary studies in general and ethical criticism in particular. If narratives can alter the beliefs of readers, then they are important tools for spreading values, emotional dispositions, and cognitive practices. This does not mean, however, that fictional narratives are necessarily moral; instead, they can be used for myriad sorts of (im)moral purposes. As Fredric Jameson asserts in his influential consideration of the ideology of form - a consideration recently adopted by Terry Eagleton - there is a close relation between formal features and ethics. However, despite Jameson's very suggestive ideas about the value of form as "immanently and intrinsically an ideology in its own right” (141, see also 99), and Eagleton's repeated emphasis of the link between the morals and the literary form of a work of literature (see Eagleton 46-51, 59), the question as to which narrative conventions shape a story's ethics - and that in turn might influence readers - has been largely neglected. The works of Catherine Harrison, Wolfgang Müller, and James Phelan are invaluable exceptions amongst a host of studies concentrating on the content of stories. In the following, I will clarify the question concerning the ethical importance of narrative conventions by combining recent research in psychology with narrative theory. I argue that it is worthwhile to take the persuasive power of fiction seriously by practicing an ethical criticism that acknowledges the importance of form, and, at the same time, developing criteria for evaluating the ethics of fictional works.

\section{The Persuasive Power of Fictional Narratives}

A large body of psychological research has demonstrated that reading stories changes readers' beliefs, their attitudes, and even their personality traits (see Mar, Oatley, and Peterson; see also Green, Brock, and Kaufmann 313; and Djikic, Oatley, Zoeterman, and Peterson, 28). At first sight, these results seem surprising: who would have thought that a simple story can induce American students to believe that eating chocolate helps you lose weight or that brushing your teeth is bad for your gums? Yet this is exactly what studies have found, and these initial findings have subsequently been replicated and broadened in scope since the end

1 Though scholars such as Jay Hillis Miller, Paul Hernadi or Wayne C. Booth assume that fiction does have an ethical importance, they do not explicitly deal with the persuasive power of fiction, define it, explore the reasons for this potential of fictional stories or relate it to formal conventions. 
of the 1990s. Moreover, it is not just factual stories that can persuade readers: indeed, though it seems unlikely that narratives which readers knew to be fictional and therefore without a factual truth-status could persuade them to change their mental encyclopaedia and general world knowledge, many experiments, like the path-breaking one conducted by Prentice, Gerrig and Bailis, have shown that fiction is just as powerful, if not more so. The morals and values embedded in literary works matter. In their overview of recent research in this area, Green and Donahue show that these morals should be taken seriously and questioned with regard to the kind of ethics that are spread via particular kinds of fiction.

To date, no definitive study has explained why stories known to be figments of the imagination can have such a potential for persuasion. ${ }^{2}$ Literary studies can build on psychological research and offer good reasons for this phenomenon. After all, the very characteristics of the reception of literature, in particular the suspension of the "fact convention" (Schmidt, 110-143, particularly 116-117, 133-138), that is, the expectation that what is being read is not referring to actual events, makes it easier to accept, for the moment, even quite strange things. Readers thereby engage with views that might otherwise, in real life, seem dubious or even threatening; in knowing that such views do not threaten one's cherished opinions, values, and current goals, the reader is opened to new experiences. Safely curled up in an armchair, it becomes possible to play with opinions and experiences too dangerous to introduce into social interaction similarly, the very fact that they are "only fictional" may be conducive to their long-term effects. Many readers, when faced with factual stories, spend cognitive effort on questioning the truth or utility of what has been read, in what is called a state of transportation or immersion in a good story; however, if readers know that a story is "just fiction," it will not seem necessary to invest cognitive energy in checking whether the content conforms to one's own world knowledge (see Green, Brock, and Kaufmann 313). Moreover, becoming immersed in a fictional world goes hand in hand with accepting it; the process of questioning the story world's facticity occurs later. The suspension of disbelief, thus, naturally accompanies the process of reading good narratives. Contrary to the Romanticist belief that the reading of fiction involves the willing suspension of disbelief, it requires more cognitive effort to suspend belief and critically scrutinize the plausibility or correctness of what has been read (see Gilbert; Schreier 332).

2 Evocriticism has dealt with related issues, and some critics emphasize the power of fiction by conceptualizing it as an adaptation, that is, fulfilling a unique and necessary role for the survival of humans and the evolution of human brains (Boyd 150). 
The reading of fiction has two possible effects that are noteworthy from the point of view of ethical criticism: first, fictional stories disseminate values and change readers' beliefs; second, reading fictional narratives or viewing fictional films can exercise cognitive and affective processes that are important for prosocial behavior and for understanding others. Literature can thus foster empathy as well as what has been termed "sensitive understanding" (Batson 267), which encompasses both affective and cognitive processes. While the first effect (changes in the reader's convictions) has been the subject of extensive psychological research, the second has not been afforded sustained critical inquiry. Until recently, it has not been asked what kind of stories can encourage readers to adopt the perspective of others, to discard former stereotypes, and to become more tolerant towards atypical characters (Nünning, Reading Fictions). In the following, I will concentrate on the second function that reading, particularly of fictional stories, can fulfill, and I will propose a few hypotheses concerning the relationships between the two.

In order to explore which narrative conventions can evoke sensitive understanding of others, it is necessary to first delineate the cognitive and affective processes involved in this kind of understanding. Though there are no unanimous definitions of key concepts, the neurosciences and psychology usually employ the term "empathy" to refer to the affective processes of "feeling like" the other while remaining aware of the difference between oneself and the other whose feelings are being shared (Singer 433 and Batson). Related feelings, which are connected to pro-social behavior, have also been referred to as sympathy, pity, compassion, and sympathetic distress (Batson, Ahmad, and Lishner); they should be distinguished from the kind of empathic sharing involved in perspective taking. "Theory of mind" abilities, in contrast, refer to the capacity of cognitively (albeit not necessarily affectively) gauging their beliefs, aims, and desires, and drawing conclusion as to which intentions they pursue. Both processes are, in different combinations, practiced in interactive encounters and in the reading of fiction; in short, the understanding of people and the understanding of fictional characters bear many resemblances. There seems to be a "shared neural basis for attempting to make sense of real people and for processing fictional representations of persons" (Mar and Oatley 180). ${ }^{3}$ Moreover, the plasticity of the brain ensures that extended and repeated practice will have biological as well as mental consequences. These affective and cognitive activities are not in them-

3 The following section, which explores the value of fiction with regard to perspective-taking, consists of a revised and drastically shortened version of my article "Cognitive Science and the Value of Literature for Life". 
selves linked to morality or altruistic behavior; on the contrary, to know just what others think and feel makes it possible to deceive or hurt them more effectively. One should therefore differentiate between the ethical and the cognitive values of fiction - the latter encompasses, for example, the broadening of the reader's understandings of both implicit personality theories and the thought processes of people completely different from the reader. Such an elaboration of implicit personality theories is a precondition for pro-social action, since one must understand the needs and feelings of others before one can put that knowledge into practice. However, there is no necessary connection between the cognitive value of literature, which has been demonstrated by Raymond Mar and his colleagues, as well as by David Kidd and Emanuele Castano and literature's ethical value.

Nonetheless, there is at least one kind of perspective-taking that can be practiced in reading fiction and that has been shown to correlate with altruistic behavior. This kind of "sensitive understanding" includes cognitive and affective processes and involves imagining how another person would feel in the same situation. In contrast, imagining oneself in the position of another is not necessarily related to altruistic behavior. Even though these two practices are closely linked, participants in experiments who were asked to adopt what psychologists term the "imagine-self" perspective, which involves imagining how oneself would feel in a given situation, not only felt different emotions but also experienced different physiological symptoms than those who were asked to take the "imagine-other" perspective (see Batson). Several conditions must be met in order to adopt such a perspective, and I argue that fictional narratives are particularly apt to fulfil these. As far as literature is concerned, the obstacles blocking perspective taking in real-life situations are negligible: fictional narratives frequently provide readers with the salient facts necessary to understand the characters as well as the particular situation in which they act; the pleasure and interest that are part of the experience of becoming immersed in fictional worlds offer an incentive to invest the necessary cognitive efforts to assume the perspectives of characters; and the problems accompanying the adoption of others' perspectives in real life are next to non-existent. The combination of these factors allows the reader to regulate his or her own perspective and to imagine what the characters feel and think, all while remaining aware of his or her differences from the characters. Reading fiction thus affords a perfect opportunity for practicing perspective taking that is, due to its manifold inherent difficulties, precarious in interactive situations (see Decety and Sommerville; and Rameson and Lieberman). 


\section{The Meaning of Form: Narrative Strategies Fostering Perspective Taking}

The conditions for the "imagine-other" perspective, involving imagining how the other feels in a given situation, are more prone to be met while reading fiction than in real life, yet this does not mean that every work of fiction induces the reader to practice this kind of understanding. Unfortunately, psychological research into the kind of narrative that unfolds fiction's persuasive power has only yielded few results. The most obvious correlation is between the reader's degree of transportation and his or her emotional engagement with the fate of the characters. This is also linked to the persuasive power of fiction: the reader must imaginatively, emotionally, and cognitively engage with the tale in order to care about the characters and to adopt the beliefs and values that are being presented. Interestingly, two factors related to the story content have been disproven: in short, neither the "homophily" between reader and protagonist (that is, the similarity between the reader and the character he or she feels empathy with) nor the "nearness of topics" (the presentation of topics that interest the reader in his or her daily activities) plays a role. According to Slater and Rouner, not even the gender of the protagonist is of importance (see also Bortolussi, Dixon, and Sopčák). Instead, what has been found to be significant in this respect are two factors, namely, the quality of the writing and the "perceived realism" of the story, both of which can be linked to stylistic features. Apparently, stories written by canonical or bestselling authors have had more impact than those produced by psychologists for the purposes of testing (Green 248-249). While this stands to reason, it does not provide enlightenment as to the features that constitute a story's quality. However, I would argue that, from the perspective of literary studies, one can point to a number of narrative conventions that encourage perspective taking. It is worth emphasizing that these conventions cannot determine how individual readers respond to a text. Readers' interpretation strategies depend on their knowledge, as well as on their (emotional) experiences and memories. It is difficult to point out textual features which usually result in perspective taking of the intended authorial audience, but there are few strategies that can ensure that someone who actively reads a text will at least share the characters' thoughts, if not their emotions. While there is a (bottom-up and topdown) interplay between textual features and cognitive information processing (Schneider, "Narrative Dynamics," 51f.), the schemata triggered by textual cues are culture-specific and the individual experiences and memories within them may differ widely. Moreover, there are variances with regard to the ability and willingness of readers to adopt characters' perspectives. Since culture plays a 
large role in how and why someone reads a text, differences between, for example, Chinese and American or Western European readers are to be expected.

A tentative analysis of the narrative strategies and stylistic features encouraging an adoption of the imagine-other perspective can begin with a story's "perceived realism." This concept, which the psychologist Melanie Green has correlated with the degree of transportation and the emotional interest of readers, does not refer to realist fiction in the narrow sense of the word; instead, it aims at the impression of readers who ascribe lifelikeness and plausibility to the story's events as well as to the feelings, intentions, and actions of the protagonists. What is in question would seem to be what Keith Oatley, another psychologist who values fictional stories because of the "vicarious experiences" they offer to readers, terms the truth of coherence, that is, the text-internal consistency of the events as well as the thoughts and feelings of the characters linked according to principles and causes that are held to prevail also in real life (Oatley, "Fiction May Be Twice," 109). Oatley's view is backed by various other experts on the field, for instance Busselle and Bilandzic. Characters like Harry Potter or the hobbit Frodo would thus meet the criterion of perceived realism. Within their respective fictional worlds, the characters act in a way that is plausible to the extent that they correspond to current folk psychology. Given the specific circumstances, readers would expect the characters to feel and think - more or less - as they do. This fits in well with the requirements for the imagine-other perspective: characters must be lifelike in the sense that they conform to beliefs about psychological processes, for this allows the reader to understand their thoughts, feelings, and actions. This does not mean, of course, that in order for characters to be perceived as lifelike they must be models of reason and internal consistency: on the contrary, small deviations or even obvious defects can prove fascinating because they remain within the bounds of the thinkable, despite also being beyond the pale of the normal. Indeed, it could even be argued that the most lifelike characters are those that are complex and carry internal contradictions. Moreover, genre conventions, individual preferences, and the cognitive abilities of readers (for instance, children as opposed to adults) each play a large role in defining what is plausible within the frame of the fictional world. In a science fiction novel or in a fantasy, for instance, wielding a lightsaber or a magic charm can be far more "realistic" than shooting a pistol.

In addition to perceived realism, one must also consider narrative conventions likely to evoke the reader's interest in the fate and mental processes of particular characters. As far as the imagine-other perspective is concerned, readers must imagine how a character feels in a specific situation, given the character's particular perspective, that is, his or her system of preconditions, which is shaped by personality traits, emotions, dispositions, beliefs, desires, and aims 
(see Hartner 150-160). Literary scholars have identified three main narrative strategies capable of prompting the reader to take the perspective of characters, to raise empathic feelings for the characters, and reduce the reader's distance to the characters. First, the adoption of characters' perspectives can be initiated by presenting their perceptions, thoughts, and feelings in a seemingly immediate way, such as via quoted thoughts, interior monologue, free indirect discourse, or psychonarration. This allows the reader to follow and empathically share the mental processes and emotions of fictional characters, and thereby reduces the distance between reader and characters. Second, narrator comments (and, at least sometimes, comments by other characters) can add to the reader's knowledge about a character's perspective or appeal to the reader to sympathize with the character. These comments can fulfil a wide spectrum of functions: they can explain a character's motives, underscore a lack of alternatives to a character's actions (which might otherwise initially appear egotistic), emphasize a character's plight and suffering, relate a character's actions to common human needs, and so on.

Though the effects of these two conventions inviting readers to share characters' thoughts and feelings are closely linked, it is necessary to distinguish between the different kinds of understanding they evoke. The first convention enables the reader to follow characters' mental processes, and is mainly concerned with the aspect of focalization and the sharing of their fleeting perceptions. The second provides knowledge about the characters and offers insight into their respective personalities and current mental states, thereby allowing the reader to understand characters and adopt their perspectives without actually following their thought processes. The first convention allows thinking like and feeling like or with the character, that is, the participation in the character's thoughts and feelings. The second provides knowledge about the characters and can, in turn, induce readers to feel for them. The latter allows for sympathy, pity, and a deeper understanding of a character's perspective. Both aspects are intricately related as far as the taking of perspectives is concerned, but they proceed via different means. Both are important for an exploration of the cognitive value of literary works; they enable the reader to vicariously experience thoughts and feelings of others and allow him or her to "simulate" characters' emotions, thereby enlarging the scope of the reader's own knowledge as well as engaging cognitive processes of crucial importance for social coexistence and interaction (see Mar and Oatley, Tooby and Cosmides on the value of simulation).

The third, and equally time-honored, mode of heightening the interest and empathy of readers is that of setting a character into a precarious position. Creating suspense and evoking a situation of potential harm is a mode of engaging the reader that is referred to as "situational empathy" (Hogan 140). Accord- 
ing to scholars like Richard Gerrig and Fritz Breithaupt, the situation and the expectations which are raised with regard to it are of major importance for the reader's emotional responses. In order to feel with (and for) characters, they must be in a situation that potentially allows for positive as well as negative endings. In such situations, the reader is prone to evaluate the future development of events in light of his or her own wishes as well as those of the characters. Scholars have stressed the relation between the fictional situation and the reader's sharing of characters' experiences and feeling; nonetheless, this narrative convention differs significantly from the others, in that it provides an incentive for investing the cognitive effort necessary for caring about a character's mental processes. Although putting a character in danger offers neither insight into his or her personality nor any means for sharing complex mental processes, it reduces the distance towards literary characters and is an important basis for the reader's willingness to take their perspectives.

It must be emphasized, however, that each of the three conventions discussed above can, by the same token, be employed in order to increase the distance between character and reader. For example, in her article "Theory of Narrative Empathy," Suzanne Keen emphasizes the difficulty in identifying - and demonstrating - the effectiveness of such strategies as first-person narration (213-214). Literary devices that enable - or force - the reader to follow the thoughts and emotions of characters or speakers may increase this distance when these mental processes contravene the reader's values or "feeling rules" (Hochschild) - for instance, when a character rejoices in the torture of another or fails to mourn the death of a friend. In particular, contemporary and multi-perspective works frequently present abhorrent, disgusting, or, at least, undesirable feelings that the reader understands though they evoke negative emotions instead of empathic sharing. Likewise, narrator comments can just as well highlight a character's egotistic and self-serving aims, which might otherwise have remained hidden. Even placing a character into a dangerous situation does not necessarily increase the reader's desire to adopt the character's perspective: indeed, it is a staple of thrillers that readers are induced to hope for the failure or even death of a one of the main characters, while feeling with his or her victim. In this respect, the character of a serial killer may serve as focalizer in precarious situations, with the reader hoping that the character will be apprehended in time. The process of sharing thoughts and emotions can therefore be reduced to a merely rational process, one which evokes disgust and antipathy rather than empathy. In such cases, adopting a character's perspective may still broaden the reader's knowledge and refine his or her personality theory, but it does not involve an evocation of similar feelings. When it comes to literary conventions, there is no form-tofunction mapping: the cognitive, as well as the ethical potential of fiction is 
shaped by a combination and arrangement of different strategies, as well as by the strategies' relations to the story's contents and to the cultural values of the time of its production.

I wish to argue that increasing the reader-character distance is of crucial importance for the process of perspective taking. Losing awareness of the difference between oneself and a character implies complete identification with the character's goals and could result in the adoption of the imagine-self perspective. This is rare, however, even as far as the empathic sharing of thoughts and feelings is concerned. In contrast to scholars such as Keith Oatley, I argue that a dual process is involved in sharing a character's thoughts and feelings. This process consists of an oscillation between two quite different cognitive activities on the part of the reader: First, there is the process of "feeling like" the character in question (Mar, Oatley, Djikic, and Mullin 824; Schneider, "Cognitive Theory," 613). Depending on the particular context, this process shifts between a more emotional and a more cognitive simulation of the character's thoughts and feelings; the latter simulation would prevail, for instance, when following the thoughts of an anti-hero or villain. Second, the process of simulation is linked to the reader's own appraisal of the situation in question. This appraisal is influenced by the reader's knowledge of the text thus far read, and can include information about events not available to the focalizer. It is also based on the reader's own experiences and what he or she wishes to see in the story's further development. This second process is intricately connected to an overall assessment of the situation and to the moral positioning of readers; it is closely related to questions of ethics. As James Phelan has noted, “[o]ur emotions and desires about both fictional and nonfictional characters are intimately tied to our judgments of them" (Living to Tell about It 160).

\section{The Ethics of Form: Narrative Strategies from an Ethical Point of View}

So far, I have stressed that the adoption of the imagine-other perspective is ethically desirable. This corresponds to the Western tradition of appreciating empathy, sympathy, and the power of literature to evoke these feelings. As the pro-social associations of the imagine-other perspective evidence, there is good reason to follow this tradition, to which authors such as George Eliot have contributed. Moreover, the kind of "ambassadorial empathy" (Keen, "Strategic Empathizing," 483-487) that raises sympathetic understanding for members of out-groups can have important beneficial consequences. Nonetheless, I wish to 
argue that both raising and blocking empathy, as well as careful orchestration and modulation of distancing devices, are at the center of an ethics of fictional form; in short, creating distance is just as important as reducing it. Especially in light of psychological studies, the use of distancing devices seems even more important, since readers tend to supply characters' emotions and thoughts without having to be told about them explicitly and without benefit of the conventions described earlier (Habermas and Diel).

With regard to the ethical value of literature, it is advantageous to differentiate between two aspects: On the one hand, there is the reduction of the distance between readers and characters, and the adoption of the imagine-other perspective. This can increase the reader's knowledge; it also exercises mental processes that can subsequently be activated in real-life situations. On the other hand, it is important to emphasize the ethical significance of distancing devices that contribute to an awareness of the differences between readers and characters. Especially in postmodern times, it is necessary to consider the experience of alterity, of the otherness of others. According to the French philosopher Alain Badiou (41), the acceptance of alterity and the radical difference between oneself and everybody else (including oneself) is a cornerstone of a theory of ethics. This view is compatible with a Levinas-inspired ethics, which has moved away from the prescriptive dimension of traditional values and towards a more tentative and open postmodern ethics. As Herbert Grabes asserts, “[i]f multiplicity, heterogeneity or alterity are the predominant features of this period, as regards both society and individual search for identity, contemporary ethics must [...] promote an ethical stance that will [...] enable us to live in it with dignity" ("Ethics, Aesthetics” 25-26). Because we live in a society marked by multiplicity, heterogeneity, and alterity, literary works have an ethical value that transcends the practice of the imagine-other perspective, for they not only enable us to appreciate this kind of heterogeneity and complexity, but also help us to accept otherness, to refrain from stereotyping and categorizing others, and to abandon the insistence on closure. This does not imply a devaluation of the kind of perspective taking described above; rather, it makes it possible to appreciate the ethical value of narrative strategies that induce both sensitive understanding of lifelike characters and the acknowledgement of instability, openness, heterogeneity, and complexity.

It therefore seems promising to briefly consider aesthetic devices that increase the distance between readers and characters. Practicing empathy is only part of a more complex cognitive process as far as altruistic behaviour is concerned: it is also necessary to differentiate between persons whom one should empathize with and those whom one should not. Moreover, distancing strategies are closely linked to the aesthetic quality of literature. Viktor Shklovsky has related this to the techniques of defamiliarization; he stresses that a major asset 
of reading literature is to make the familiar appear strange, to change ingrained paths of perception, and to enhance the cognitive effort of understanding the represented elements (12-13). According to Shklovsky, literature can enable readers to break from routines, to see - and appreciate and evaluate - things anew. Defamiliarizing devices, which slow the reading process and enhance the distance of what is being described to the reader (who must puzzle out what is meant) can also open the space necessary for questioning stereotypes and prejudices and for affectively engaging with characters who may initially seem strange. On the basis of Shklovsky's insights, David Miall and Don Kuiken claim that aesthetic devices instigate a "a three-phase structure in response" (299) that encourages readers to search for a new context in order to comprehend the defamiliarizing phrase, metaphor, or attitude, and ultimately achieve deeper understanding.

However, defamiliarizing devices do not always lead to cognitive closure; from an ethical perspective, what seems to be even more important is the flexibility and openness such devices require of readers. For example, it is frequently impossible to categorize characters; especially in modernist works, the first description of a figure often amounts to nothing more than hints about their opinions, attitudes, or dispositions. Ambiguity and uncertainty often feature in fictional stories, and this kind of polyvalence relates to the power of fiction to engage readers' emotions as well as their interests. Moreover, the dynamics of the reading process must be taken into account: the same character may appear in a different light in separate situations, and, until the end of the story, it may remain uncertain whether or not there will be a reversal that will necessitate a revision and reinterpretation of the story's events. In contrast to our routines in everyday life, in reading fiction our first impressions are often questioned and need to be revised. Even in some types of formula fiction - for example, romance pageturners and detective novels - part of the suspense is engendered by uncertainty about whether a character is indeed what he or she seems. In many cases, it is possible in retrospect to recognize former misunderstandings and to reinterpret events in light of these new insights; in other cases, the uncertainty concerning the evaluation of a character remains. Some literary texts necessitate the acknowledgement of complexity and otherness as well as only partial comprehension; they deny cognitive closure and complete comprehension.

In particular, multi-perspective texts that present a wide range of heterogeneous characters - and the personality traits, values, and emotional dispositions they embody - can initiate a number of cognitive activities that add to the ethical value of fiction. Shifts in focalization, which call for rapid adjustment to different points of view, can enhance the effects of defamiliarization. This change between focalizers becomes more demanding if characters' respective perceptions are not 
easily reconciled, if characters interpret and evaluate an object or situation in different ways. Henrike Moll and Andrew Meltzoff, in their studies of child development, have stressed that there is a huge difference between, on the one hand, taking the perspective of a character and, on the other, "confronting" different perspectives and dealing with heterogeneous points of view (672). This differentiation is also important for understanding the cognitive and the ethical value of reading fiction. Encountering a story's events via a character's perceptual and cognitive point of view encourages the reader to take the character's perspective and share in his or her feelings; however, the presentation of contradictions between different characters' perspectives makes it necessary that the reader gains distance from them. The reader must simultaneously share and critically evaluate the characters' views and decide whether to adopt the interpretation given by one character over that of another - or to arrive at a completely different interpretation, on the basis of their own (superior) knowledge. This implies that the reader must choose which characters to empathize with and which to maintain distance from. Contradictory perspectives and shifts in focalization not only highlight the heterogeneity of perception and feeling; they also ask the reader to practice a cognitively complex process of “confronting” perspectives and forming his or her own opinions as well as positioning oneself in the face of such contradictions. A similar potential for foregrounding inconsistencies lies in the use of dramatic irony, which signifies a discrepancy of knowledge between the character or narrator and the reader, who is in a position to recognize the former's errors. Various other aesthetic devices can also guide the processes of perspective taking. It is infeasible to discuss them here, as an effective and detailed account would have to explore, among other things, conventions concerning the handling of time and the importance of ambiguities and gaps or blanks (Iser 67, 68).

Multi-perspective works especially necessitate the interpretation, evaluation, and weighting of different perspectives. In order to arrive at an understanding of an event that has been presented from the respective points of view of different characters, the reader must assess not just the characters' reliability and their comprehension of the facts but also their moral values. The reader's ethical response is relatively clearly guided by the text when both bonding and distancing devices tend to work toward the same ethical purpose. Notable examples of such texts include those eighteenth-century and Victorian novels that heeded the maxim of the "just distribution of sympathy," with villains being presented in an unfavorable light and heroes in a favorable one. ${ }^{4}$ Especially in modernist and

4 Even in the eighteenth century, it was not always easy for authors to ensure that readers would discern the textual story in the author's intended way. For example, Samuel Richardson found 
postmodernist works, however, it is frequently impossible to arrive at a conclusion that categorizes the respective views and values as either "reliable" and "ethically sound" or as "untrustworthy." The heterogeneity of even a single character's thoughts, feelings, and dispositions often impedes such judgments; the comfort of cognitive closure remains beyond reach. Readers are encouraged to accept alterity and heterogeneity. They practice a process that, from an ethical perspective, is arguably as valuable as adopting the perspectives of others. In literary works, this process is guided by distancing and engaging devices. Narrative conventions that reduce the distance towards the characters invite the reader to empathically share the characters' thoughts and to develop an understanding of and fellow feeling with different, even mutually exclusive, viewpoints. ${ }^{5}$ If at least some of the focalizers or narrators can engage the reader's sympathy, it becomes more difficult to condemn their limitations and depreciate them as being untrustworthy. The complexity and denial of closure inspired by the use of narrative forms can thus induce readers to comprehend contradictory positions, thereby rendering alterity more acceptable and moving towards an ethics of alterity.

The ethical implications of particular combinations of bonding and distancing devices are even more complex in works that foreground the question of the reliability of narrators or focalizers (Phelan, "Estranging Unreliability"). Unreliable narration is per se a problematic narrative device as far as the ethics of a novel are concerned. After all, unreliable narrators usually tell their story from their own point of view; particularly those sincere, but in some way misguided, deviant or mentally ill character narrators that Booth (304) and many others dealt with allow us insight into their thought processes and justify their behaviors in accordance with their own norms, trying to encourage the reader to empathize with them. A skillful handling of free indirect discourse may allow for some degree of ironic distancing between the narrator and the focalizer, which a careful reader may discern - but with regard to unreliable narrators this kind of distance simultaneously becomes crucial and problematic. The relation between ethics and unreliable narrators with questionable norms and values is thus fraught with

that the villain of his novel Clarissa (published in 1748) actually evoked the sympathy of many of his intended readers. Moreover, the dynamics of the reading process must be taken into account: just as the same character may appear in a different light in different situations, the relations between characters shift, and heroes may appear less admirable and villains less despicable at different stages of the text. I owe this reference concerning the wide spectrum between the bonding and distancing devices in the same narrative text to the editors of this volume.

5 For a discussion of such narrators in recent British novels, see my article "Ethics and Aesthetics," on which the following arguments are based. 
contradictions. On the one hand, the confrontation with radically different views may establish this kind of fiction as a valuable vehicle for ethics, because it evokes an experience of alterity. On the other hand, the reader's gaining of insight into the consciousness of morally suspect narrators and being invited to share such narrators' thoughts and feelings may lead to a development of sympathy for both the narrators and their questionable ethics. Moreover, the confrontation with - ethically questionable - unreliable narrators or focalizers can serve a function that is ethically important: these narrators may initiate self-reflection into the reader's own, differing values and principles. After all, cognitively following the thoughts of narrators or characters does not necessarily imply either affective sharing or a loss of critical distance on the part of the reader. On the contrary, the exposure to offensive views and feelings may, especially in novels that feature contrasting perspectives or elicit pity for the narrator's victims, lead to disgust and to a reaffirmation of the reader's values.

A similar, perhaps even more important, kind of ethical reflection can be inspired by multi-perspective works featuring heterogeneous perspectives that can neither be reconciled with each other nor discarded as irrelevant or simply wrong. Such novels, which require openness and acceptance of ambiguity and complexity on the part of readers, implicitly raise the question of whether there are absolute ethical values. These works raise readers' awareness with regard to the hierarchization of values or the problems of neatly distinguishing between "acceptable" and "unacceptable" positions. The same function can be fulfilled by novels that include several narrators or present only a particular point of view while hinting at other, equally valid ones. The use of narrative bonding and distancing devices thus emphasizes the problem that there might be - as claimed by Alain Badiou (43, 61, 65-81), for example - no ethics "in the abstract" but only an "ethics of truths," which acknowledges that truth can only be related to (and come into being in) particular situations and particular individuals. The awareness of and reflection on such an "ethics of truths" can be enhanced through a use of narrative conventions that leads readers to care about characters, to become involved in characters' fates, and to adopt their perspectives, yet which at the same time require the recognition of the heterogeneity of and contradictions between the positions the characters embody.

These observations concerning the initiation of ethical reflections on the reader's own values already point toward relationships between the two possible effects of reading fiction: on the one hand, the dissemination of values and effecting change of the reader's beliefs, and, on the other, the practice of cognitive and affective processes important for understanding human beings. The topic certainly merits further attention, but I would like to suggest that three interrelations especially warrant exploration. First, the process of taking perspectives and arriving at a 
deeper understanding of the beliefs, emotions, and actions of fictional characters may lead to a higher appreciation of perspective taking and a recognition of its importance for behaving responsibly in complex social situations. Second, shifts from categorization to individuation and the discarding of stereotyping a particular character may engender a change of attitude towards particular stereotypes or an awareness of the problems of stereotyping in general. Third, taking the perspectives of characters and temporarily adopting their values and traits may lead to a reflection on and appraisal of these values and thereby result in the dissemination of values. It should be emphasized that the latter two of these relationships are interconnected, since a high appreciation of a particular attitude or personality trait embodied by a character will enhance the reader's willingness to adopt that character's perspective and to shift from categorization to individuation.

In addition, both possible ethical effects of reading fiction depend on the reader's transportation. They are also closely related to the reader's willingness and ability to become emotionally and cognitively immersed into the story world. While it has been shown that engaging the reader's emotions enhances the degree of transportation and the persuasiveness of a story, there may also be a reciprocal relation with highly ethical texts that involve readers' emotions to a greater extent than do other works. ${ }^{6}$ There thus seems to be a two-way interaction between ethics and emotions, which may account for the persistent persuasiveness and appeal of certain literary fictions that have continued to fascinate readers through the ages.

\section{Conclusion: Fields of Research for a Cognitively Informed Ethical Criticism}

Reading fiction is not just a pleasurable pastime. It conveys values, exercises cognitive and affective processes, and shapes readers' minds. The ethical importance of literature has been stressed by scholars in both Western and Eastern countries. Rarely, however, has it been attempted to consider insights from psychology and cognitive studies in order to link the use of particular constellations of narrative conventions to specific kinds of ethical values. While the effects of particular narrative conventions always depend on their specific combination and weighting as well as on the content and context of the particular work, two aspects merit consideration with regard to the analysis of the ethical value of

6 I owe this suggestion to Shang Biwu and Nie Zhenzhao. 
specific works of literature: first, the power of literature to encourage readers to adopt and practice the imagine-other perspective and, closely related, the use of narrative conventions that reduce the distance to lifelike characters; and, second, the importance of distancing devices and of strategies enhancing the work's complexity and denying the reader cognitive closure. These seemingly contradictory narrative conventions often occur in combination with each other, and a more or less balanced mixture between them seems to correspond to major features of post-modern ethics - the sharing of experiences of lifelike characters in complex works that resist easy answers and encourage readers to accept and even appreciate heterogeneity and alterity.

However, many questions remain open, especially as far as the effects of the arrangement of specific narrative strategies are concerned. A framework for understanding such combinations has been sketched here, yet this could be further detailed and modified in any number of ways worthy of exploration. Which constellations of particular devices reduce the distance between reader and character and invite the reader to feel with and for the character in question? To what extent are these combinations subject to historical change, what role is played by cultural values, and is it possible to relate specific constellations to specific genres? Are there particular devices that can be identified in a large number of cases (at least as far as the adult readers are concerned), such as placing the protagonist in a precarious situation, admiring and understanding comments from other "ideal characters," and concentrating on the protagonist's point of view, as might be suggested by a look at eighteenth-century devices still in use today (for example, see my article "Voicing Criticism")? And, last but not least, what role do specific cultural models play as far as concerns, for instance, features about the contents of the work or the depiction of the characters? How do characteristics such as physical attractiveness, (generally) ideal personality traits, and emotional dispositions relate to the use of formal conventions?

The number of open research questions could daunt scholars into surrendering before even making any attempt. However, there are good reasons for endeavoring to address these problems. The persuasive power of fiction is a fact: fictional stories have an ethical impact - and literary and cultural scholars seem to be the only people with the requisite expertise not only to explore the dissemination of values in given (popular) texts and films, but also to analyze which ethically valuable practices become initiated in the reading of such works. At a moment when the legitimization of literary scholarship has become an urgent problem in many countries, the promise of such a benefit is particularly stimulating and justifying. 


\section{Works Cited}

Badiou, Alain. Ethik: Versuch über das Bewusstsein des Bösen (Ethics: An Essay on the Understanding of Evil). Trans. Jürgen Brankel. 1993. Wien: Turia und Kant, 2003.

Batson, Daniel C. "Two Forms of Perspective Taking: Imagining How Another Feels and Imagining How You Would Feel." Handbook of Imagination and Mental Simulation. Eds. Keith Markman, William Klein and Julie Suhr. New York: Psychology Press, 2009. 267-279.

Batson, Daniel C., Marina P. Polycarpou, Eddie Harmon-Jones, Heidi J. Imhoff, Erin C. Mitchener, Lori L. Bednar, Tricia R. Klein, and Lori Highberger. "Empathy and Attitudes: Can Feeling for a Member of a Stigmatized Group Improve Feelings Toward the Group?” Journal of Personality and Social Psychology 72.1 (1997): 105-118.

Batson, Daniel C., Nadia Ahmad, and David A. Lishner. "Empathy and Altruism." Oxford Handbook of Positive Psychology. Eds. Shane J. Lopez, and C.R. Snyder. Oxford: Oxford UP, 2009. 417-426.

Booth, Wayne C. The Rhetoric of Fiction. Chicago: U of Chicago P, 1961.

Bortolussi, Marisa, Peter Dixon, and Paul Sopčák. “Gender and Reading." Poetics 38 (2010): 299-318.

Boyd, Brian. "Evolutionary Theories of Art." The Literary Animal: Evolution and the Nature of Narrative. Eds. Jonathan Gottschall and David S. Wilson. Evanston, IL: Northwestern University Press 2005. 147-178.

Breithaupt, Fritz. Kulturen der Empathie (Cultures of Empathy). Frankfurt a. M.: Suhrkamp, 2009.

Busselle, Rick, and Helena Bilandzic. "Fictionality and Perceived Realism in Experiencing Stories: A Model of Narrative Comprehension and Engagement." Communication Theory 18.2 (2008): 255-280.

Cohen, Jonathan. "Defining Identification: A Theoretical Look at the Identification of Audiences with Media Characters." Mass Communication and Society 4.3 (2010): 245-264.

de Vignemont, Frédérique, and Tania Singer. “The Empathic Brain: How, When and Why?" Trends in Cognitive Sciences 10 (2006): 435-441.

Decety, Jean, and Jerry A. Sommerville. "Shared Representations Between Self and Others: A Social Cognitive Neuroscience View.” Trends in Cognitive Science 7 (2003): 527-533.

Djikic, Maja, Keith Oatley, Sara Zoeterman, and Jordan B. Peterson. “On Being Moved by Art: How Reading Fiction Transforms the Self." Creativity Research Journal 21.1 (2009): 24-29.

Eagleton, Terry. The Event of Literature. New Haven: Yale UP, 2012.

Gerrig, Richard J. Experiencing Narrative Worlds. New Haven: Yale UP, 1993.

---. "Perspective as Participation." New Perspectives on Narrative Perspective. Eds. Willie van Peer, and Seymour Chatman. Albany: State U of New York P, 2001. 303-323.

Gerrig, Richard J., and David Allbritton. "The Construction of Literary Character: A View from Cognitive Psychology.” Style 24 (1990): 380-391.

Gilbert, Daniel S. “How Mental Systems Believe.” American Psychologist 46.2 (1991): 107-119.

Grabes, Herbert. "Ethics, Aesthetics, and Alterity." Ethics and Aesthetics: The Moral Turn of Postmodernism. Eds. Gerhard Hoffmann and Alfred Hornung. Heidelberg: C. Winter, 1996. 13-28.

---. "The Processualities of Literature." Journal of Literature and Art Studies 3.1 (2013): 1-8.

Green, Melanie C. "Transportation into Narrative Worlds: The Role of Prior Knowledge and Perceived Realism.” Discourse Processes 38.2 (2004): 247-266. 
Green, Melanie C., Timothy C. Brock, and Geoff F. Kaufman. "Understanding Media Enjoyment: The Role of Transportation into Narrative Worlds." Communication Theory 14.4 (2004): 311-327.

Green, Melanie C. and John Donahue. "Simulated Worlds: Transportation into Narratives." Handbook of Imagination and Mental Simulation. Eds. Keith D. Markman, William Klein, and Julie Suhr. New York: Psychology Press, 2009. 241-254.

Habermas, Tilman, and Verena Diel. "The Emotional Impact of Loss Narratives: Event Severity and Narrative Perspectives.” Emotion 10.3 (2010): 312-323.

Harrison, Mary-Catherine. "How Narrative Relationships Overcome Empathic Bias: Elizabeth Gaskell's Empathy across Social Difference.” Poetics Today 32.2 (2011): 255-288.

Hartner, Marcus. Perspektivische Interaktion im Roman. Kognition, Rezeption, Interpretation (Perspectival Interaction in the Novel: Cognition, Reception, Interpretation). Berlin, Boston: de Gruyter, 2012.

Hernadi, Paul. "Why is Literature: A Coevolutionary Perspective on Imaginative Worldmaking." Poetics Today 23.1 (2002): 21-42.

Hochschild, Arlie R. The Managed Heart. Commercialization of Human Feeling. Berkeley: $U$ of California P, 1983.

Hogan, Patrick Colm. The Mind and Its Stories: Narrative Universals and Human Emotion. Cambridge: Cambridge UP, 2003.

Iser, Wolfgang. Der implizite Leser: Kommunikationsformen des Romans von Bunyan bis Beckett (The Implied Reader: Patterns of Communication in Prose Fiction from Bunyan to Beckett). München: Wilhelm Fink, 1972.

Jameson, Fredric. The Political Unconscious: Narrative as a Socially Symbolic Act. [1981] London: Methuen, 1983.

Keen, Suzanne. “A Theory of Narrative Empathy.” Narrative 13 (2006): 207-236.

---. Empathy and the Novel. Oxford: Oxford UP, 2007.

---. "Strategic Empathizing: Techniques of Bounded, Ambassadorial, and Broadcast Narrative Empathy." Deutsche Vierteljahreszeitschrift für Literaturwissenschaft und Geistesgeschichte 82.3 (2008): 477-493.

Kidd, David C., and Emanuele Castano. "Reading Literary Fiction Improves Theory of Mind." Science 342 (2013): 377-381.

Mar, Raymond A., and Keith Oatley. "The Function of Fiction is the Abstraction and Simulation of Social Experience." Perspectives on Psychological Science 3 (2008): 173-192.

Mar, Raymond A., Keith Oatley, and Jordan B. Peterson. "Exploring the Link Between Reading Fiction and Empathy: Ruling Out Individual Differences and Examining Outcomes." Communications 34.4 (2009): 407-428.

Mar, Raymond A., Keith Oatley, Maja Djikic, and Justin Mullin. "Emotion and Narrative Fiction: Interactive Influences Before, During, and After Reading." Cognition \& Emotion 25.5 (2010): 818-833.

Miall, David S., and Don Kuiken. “Shifting Perspectives: Readers' Feelings and Literary Response.” New Perspectives on Narrative Perspective. Eds. Willie van Peer and Seymour Chatman. Albany: State U of New York P, 2001. 289-302.

Miller, Jay Hillis. "Should We Read or Teach Literature Now?" Anglia 129 (2011): 1-11.

Moll, Henrike, and Andrew N. Meltzoff. "How Does It Look? Level 2 Perspective-Taking at 36 Months of Age.” Child Developement 82 (2011): 661-673.

Müller, Wolfgang G. „Moralische Implikationen erzähltechnischer Innovationen bei Jane Austen (Moral)." Ethik und Moral als Problem der Literatur und Literaturwissenschaft (Ethics and 
Morality as Problems of Literature and Literary Studies). Eds. Jutta Zimmermann and Britta Salheiser. Berlin: Duncker \& Humblot, 2006. 117-132.

Nünning, Vera. "Ethics and Aesthetics in British Novels at the Beginning of the Twenty-First Century." Ethics in Culture: The Dissemination of Value Through Literature and Other Media. Eds. Astrid Erll, Herbert Grabes, and Ansgar Nünning. Berlin: Walter de Gruyter, 2008. 369-392.

---. "Voicing Criticism in Eighteenth-Century Novels by Women: Narrative Attempts at Claiming Authority." English Past and Present. Selected Papers from the IAUPE Malta Conference in 2010. Ed. Wolfgang Viereck. Frankfurt a. M.: Peter Lang, 2012. 81-108.

---. "Cognitive Science and the Value of Literature for Life." Values of Literature. Eds. Hanna Meretoja, Saija Isomaa, Pirjo Lyytikäinen, and Kristina Malmio. Amsterdam: Brill Rodopi 2015. 85-106.

---. Reading Fictions, Changing Minds: The Cognitive Value of Fiction. Heidelberg: Winter 2014.

Oatley, Keith. "Why Fiction May Be Twice as True as Fact: Fiction as Cognitive and Emotional Simulation" in: Review of General Psychology 3 (1999): 101-117.

---. "Communications to Self and Others: Emotional Experience and Its Skills." Emotion Review 1.3 (2009): 206-13.

Phelan, James. Living to Tell about It: A Rhetoric and Ethics of Character Narration. Ithaca, London: Cornell UP, 2005.

---. "Estranging Unreliability, Bonding Unreliability, and the Ethics of Lolita." Narrative 15.2 (2007): 222-238.

Prentice, Deborah A., Richard J. Gerrig, and Daniel S. Bailis. "What Readers Bring to the Processing of Fictional Texts." Psychonomic Bulletin \& Review 4.3 (1997): 416-420.

Rameson, Lian, and Matthew D. Lieberman. "Empathy: A Social Cognitive Neuroscience Approach.” Social and Personality Psychology Compass 3.1 (2009): 94-110.

Schmidt, Siegfried J. Grundriß der Empirischen Literaturwissenschaft. Frankfurt a. M.: Suhrkamp, 1991.

Schneider, Ralf. "Toward a Cognitive Theory of Literary Character: The Dynamics of Mental-Model Construction." Style 35 (2001): 607-642.

---. "New Narrative Dynamics? How the Order of a Text and the Reader's Cognition and Emotion Create Its Meanings." Germanisch-Romanische Monatsschrift 63.1 (2013): 47-68.

Schreier, Margrit. "Belief Change Through Fiction. How Fictional Narratives Affect Real Readers." Grenzen der Literatur. Zu Begriff und Phänomen des Literarischen. Eds. Simone Winko, Fotis Jannidis and Gerhard Lauer. Berlin and New York: de Gruyter, 2009. 315-337.

Shang, Biwu. In Pursuit of Narrative Dynamics. A Study of James Phelan's Rhetorical Theory of Narrative. Bern: Peter Lang, 2011.

Shklovsky, Viktor. “Art as Technique” [1917]. Russian Formalist Criticism. Four Essays. Eds. Lee T. Lemon and Marion J. Reis. Lincoln: U of Nebraska P, 1965. 3-24.

Singer, Tania. "The Neuronal Basis and Ontogeny of Empathy and Mind Reading: Review of Literature and Implications for Future Research." Neuroscience and Biobehavioral Reviews 30.6 (2006): 855-863.

Slater, Michael D., and Donna Rouner. "Entertainment-Education and Elaboration Likelihood: Understanding the Processing of Narrative Persuasion." Communication Theory 12.2 (2002): 173-891.

Tooby, John, and Leda Cosmides. "Does Beauty Build Adapted Minds? Toward an Evolutionary Theory of Aesthetics, Fiction and the Arts." SubStance. A Review of Theory and Literary Criticism 30 (2001): 6-27. 